\title{
Sexual health in young people: Issues to ponder
}

\author{
Bilesha Perera \\ Department of Community Medicine, Faculty of Medicine, University of Ruhuna, Galle, Sri Lanka \\ (Extract of the GMA oration delivered during the 2010 Annual Academic Sessions) \\ Correspondence:Dr.Bilesha Perera (pperera@indiana.edu)
}

\section{Introduction}

Having sex is one of the most pleasurable experiences a person can have if done in a proper behavior and a healthy way. Unfortunately, unhealthy sexual behavior is common in many communities across the world today, and they are a great threat to the health of the people (1-3). Globally, curable sexually transmitted infections (STIs) accounts for 340 million new cases each year which cause unnecessary ill health and deaths which could be avoided by better education, earlier diagnosis and treatment (4). An estimated 20 million unsafe abortions took place in the year 2003, $98 \%$ of them in developing countries with restrictive abortion laws (5). Worldwide, approximately $15 \%$ to $25 \%$ of women and $5 \%$ to $15 \%$ of men were sexually abused when they were children (4-6). Not only the victims of these ill-health conditions suffer, but, each of these problems carries with it the potential for lifelong consequences for families, communities, and the nations as a whole. Sexual health is a fundamental part of human life and a core component of personality and it requires a positive and respectful approach to sexuality and sexual relationships. The WHO affirms that to attain and maintain sexual health, the sexual rights of all persons must be protected, respected and fulfilled $(2,7)$. However, there are serious disparities among the populations affected by sexual health problems. The economically disadvantaged, racial and ethnic minorities, persons with different sexual identities, and adolescents often bear the heaviest burden.

In Sri Lanka, a total of 3,192 STI cases were reported to the National STD / AIDS control program in Sri Lanka in 1996 and by 2003 that figure had grown to 8233 ; a $157 \%$ increase over seven years (8). Although Sri Lanka has maintained a lower HIV prevalence rate, the fact that countries in South and South East Asia have the second highest number of
AIDS deaths, Sri Lankan population is at risk of increasing its HIV/AIDS prevalence (9). Annually, an estimated 150,000 - 200,000 induced abortions occur in Sri Lanka (10) and sexual exploitation of children has become a considerable public health problem in the country $(11,12)$. Despite the efforts made by health and education authorities in the country these health problems continue to spread throughout the country.

The sexual and reproductive health needs of adolescents differ from those of adults, and are inadequately served in many parts of the world (1315). Adolescents and young people are disproportionately affected by adverse sexual health problems. For example, half of the new HIV infections occur among young people, aged 15-24 (13). About a quarter of the population of Sri Lanka consists of young people aged between 10-24 years. But, they have not been the primary focus in many reproductive and sexual health research conducted in the country in Sri Lanka. To enjoy the important benefits of sexuality, while avoiding negative consequences, some of which may have long-term or even life-time implications, it is necessary for young people (15-24 years) to be sexually healthy, to behave responsibly, and to have a supportive environment to protect their own sexual health, as well as that of others. Information on sexual behavior of young people, and their needs and perspectives in sexual and reproductive health are essential to shape our preventive and curative health care services of young people to meet the demands. The key lies in providing young people with the information and facilities they need to make safe and healthy sex choices that are not based on other people's ideologies.

This paper basically reviews several studies conducted by me over the last 15 years on the prevalence, attitudes and needs of sexual behavior of 
young people in Sri Lanka and discusses their implications for policies and programs, and highlights the research gaps. Several recommendations on how to improve the sexual health of young people are described at the end of the paper. Institutional Review Boards (IRB) approvals for the research have been obtained from the relevant institutes for all research studies discussed in this paper.

\section{Sexual behavior and associated factors}

A significant proportion of young people in the country are sexually active and the majority of those sexually active young people are engaged in unsafe sexual practices (16-19). A study conducted in 1996 $(\mathrm{N}=446)$ on a sample of late adolescents in a southern district in Sri Lanka (16) revealed that nearly a half of the males and one third of females were sexually active before the age of 20. Males reported higher rates of all forms of sexual acts compared to females (Figure). The percentage of students having sexual experiences increased with increasing age. In this sample, among those who have had vaginal sex experience, only $20 \%$ and among those who have had anal sex experience, only $13 \%$ had reported the use of condoms in their sexual activities.

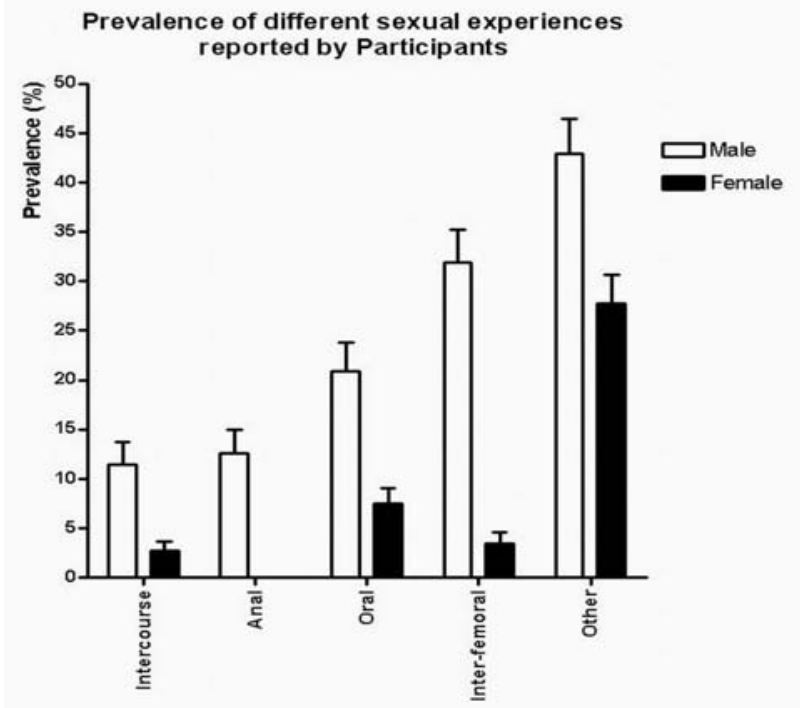

Figure: Prevalence (with 95\% CI) of different types of sexual behavior by gender

Another study ( $\mathrm{N}=3134)$ on sexual behavior of late adolescents conducted in six districts in Sri Lanka in 2000-2001(18) showed that 28\% of females and 55\% of males were sexually active, i.e. having had some form of sexual activity with a partner at least once in the past year $(p<0.01)$. Overall, $20.1 \%$ of males and $3.1 \%$ of females reported having had penetrative intercourse (anal and/or vaginal) with a partner ( $p<$ $0.01)$. Inter-femoral sex is known to be popular in this culture and $4.2 \%$ of females reported having had inter-femoral sex with an opposite gender partner and significantly more males, $20.7 \%$, reporting the same $(P<0.01)$. The overall reported prevalence of having been forced to participate in sexual activities was higher among males (19.1\%) than females $(11.6 \%, p<0.01)$.

Among males, having had a previous non-sexual relationship with another person $(\mathrm{OR}=2.91,95 \% \mathrm{CI}$ : 2.05 to 4.13 ,), occasional use of tobacco $(\mathrm{OR}=1.48$, $95 \%$ CI: 0.93 to 2.35 ), occasional use of alcohol $(\mathrm{OR}=1.64,95 \% \mathrm{CI}: 1.06$ to 2.54$)$ and occasional use of illegal drugs $(\mathrm{OR}=4.31,95 \% \mathrm{CI}: 2.47$ to 7.52$)$ were identified as predictors of vaginal intercourse. For females, having had a previous non-sexual relationship with another person $(\mathrm{OR}=2.99,95 \%$ CI: 1.61 to 5.53) was identified as important predictor of vaginal sex experience.

\section{Child sexual abuse}

A considerable proportion of children and young people in Sri Lanka is believed to be subjected to some form of sexual abuse at least once during their childhood or young adulthood though we do not have reliable and valid data on this subject $(11,12,20)$.

In a survey $(\mathrm{N}=2389)$ conducted in 2006 - 2007 using a sample of late adolescent school children in the Southern Province (21), it was observed that among boys, $13.8 \%$ were subjected to minor or severe form of sexual abuse at least once during their lifetime. The corresponding figure for girls was $14.4 \%$. Girls were more likely to report that someone had tried to touch them in a sexual way against their will. Bivariate analyses of sexual abuse by gender, socioeconomic status (SES), subject stream, and residence indicated that students with lower SES were less likely to report having been sexually abused than those with middle and upper SES. Students studying science and mathematics were more likely to report having been sexually abused. Students not living with their parents were also more likely to report sexual abuse. 
Table: Prevalence(\%) of behavioral and psycho-social risk factors and Odds Ratios (OR) with 95\% confidence intervals of reporting any form of sexual abuse by these factors; stratified by gender

\begin{tabular}{|c|c|c|c|c|c|c|}
\hline \multirow[t]{2}{*}{ Variable } & \multicolumn{3}{|c|}{ Male } & \multicolumn{3}{|c|}{ Female } \\
\hline & $\%$ & OR & $95 \% \mathrm{CI}$ & $\%$ & OR & $95 \% \mathrm{CI}$ \\
\hline \multicolumn{7}{|l|}{ Self-esteem } \\
\hline Moderate or high & 97.9 & 1.00 & & 9.3 & 1.00 & \\
\hline Low & 2.1 & 2.96 & $1.10-7.99$ & 1.7 & 0.79 & $0.21-3.11$ \\
\hline \multicolumn{7}{|c|}{ Suicidal Ideation (life time) } \\
\hline No & 91.6 & 1.00 & & 89.5 & 1.00 & \\
\hline Yes & 8.4 & 1.64 & $0.94-2.89$ & 10.5 & 2.87 & $1.79-4.60$ \\
\hline \multicolumn{7}{|l|}{ Family Conflict } \\
\hline No & 82.9 & 1.00 & & 82.0 & 1.00 & \\
\hline Yes & 17.1 & 1.75 & $1.12-2.71$ & 18.0 & 1.80 & $1.23-2.85$ \\
\hline \multicolumn{7}{|c|}{ Alcohol use (life time) } \\
\hline No & 63.0 & 1.00 & & 89 & 1.00 & \\
\hline Yes & 37.0 & 2.03 & $1.33-3.12$ & 11 & 2.80 & $1.76-4.45$ \\
\hline \multicolumn{7}{|l|}{ Smoking (life time) } \\
\hline No & 72.6 & 1.00 & & 98.1 & 1.00 & \\
\hline Yes & 27.4 & 1.04 & $0.66-1.62$ & 1.9 & 2.21 & $0.81-5.99$ \\
\hline \multicolumn{7}{|l|}{ Body Mass Index } \\
\hline Normal & 33 & 1.00 & & 35.5 & 1.00 & \\
\hline Under & 62.6 & 1.65 & $0.55-4.92$ & 61.8 & 0.96 & $0.33-2.81$ \\
\hline Obese & 4.4 & 1.35 & $0.46-3.96$ & 2.7 & 0.99 & $0.34-2.84$ \\
\hline
\end{tabular}

In multivariate analyses (Table), the odds of sexual abuse reported by boys were significantly higher among those who had low self-esteem, those who reported having consumed alcohol, and those who reported family conflict. Among females, the relative odds of sexual abuse experience were significantly higher among those who reported suicidal ideation, among those who reported having consumed alcohol, and among those who reported family conflict.

\section{Sex education and counseling}

Properly designed school sex education programs reduce the incidence of unhealthy sexual acts in adolescents (22). However, In Sri Lanka no such comprehensive sex education program is available for adolescents. In the study conducted in 2000 2001 (18), $79.6 \%$ of males and $80.7 \%$ of females reported that they learned about reproductive and sexual health issues in school through secondary level science or higher secondary level zoology. However, qualitative interviews that we conducted with students revealed that teachers were reluctant to discuss some important issues such as safe sex and preventing rape, and students were not able to get answers for their specific individual sexual health matters. In this study, significantly more males $(26.4 \%)$ than females $(12.7 \%)$ had participated in out-of-school sexual health programs conducted by non-governmental or governmental health education agencies in Sri Lanka $(\mathrm{p}<0.01)$. The majority, $60 \%$ of females reported that their mother would be the first choice for consultations related to sexual health, 
compared to only $12 \%$ of males $(p<0.01)$. Peers were the first choice of sexuality related consultation for $57.6 \%$ of males and $22.8 \%$ of females $(p<0.01)$.

In the study conducted in 2006 - 2007, gender difference was observed with regard to seeking advice on sexual health issues. Among males, $60.6 \%$ and among females $44.5 \%$ were of the opinion that one could seek advice from peers about sexual health problems. Mother was the first choice for seeking sexual advice for $64.2 \%$ of females, but only for $16.7 \%$ of males, while peers were the first choice for $6.6 \%$ of females and for $23.9 \%$ of males. A medical doctor was the first choice for getting sexual advice for $5.8 \%$ of females and for $20.3 \%$ of males. In males, $51.4 \%$, and in females, $59.3 \%$ reported the presence of a student counselor or a student counseling service in their school. Among those who reported having a student counselor or a counseling service in their school, only $19.0 \%$ of males and $11.3 \%$ of females reported ever having used such a service.

\section{Addicted to sex: An emerging public health issue}

There are people who are addicted to alcohol, food, work etc, but are there people who are addicted to sex? In the last two decades there has been an intense debate among clinicians, sexologists, sociologists, behavioral scientists and other sexual health professions over appropriate designations and definitions for out-of-control sexual behavior (2325). Some argued that excessive sexual behavior is a separate mental disorder that should be treated with appropriate medical and therapeutic interventions, while others claimed that it is a socially constructed entity, that if problematic, would require identifying and dealing with in the context of socio-cultural causative factors. Clear understanding of the nature of and personal dispositions associated with this construct is essential to formulate effective preventive or curative interventions for those who are adversely affected by their "excessive" or "problematic" sexual behaviors. To date only a handful of studies have been conducted on personal dispositions toward out-of-control sexual behaviors such as sexual compulsivity $(25,26)$ in young people such as university undergraduates.

As a part of a health behavior survey, a sample of 480 undergraduates (338 females and 142 males) in a southern university was surveyed in 2003 to identify associations between sexual compulsivity and some demographic and behavioral characteristics. The mean age of the sample subjects was 23.9 years $(S D=$ 0.97). The mean values on the measure of sexual compulsivity were $7.14(S D=5.71)$ for males and $3.28(S D=3.96)$ for females $(p<0.01)$. Use of alcohol and smoking, and suicidal behavior were associated positively with sexual compulsive behavior of the participants $(p<0.05)$. As expected, the mean scores of the sexual compulsivity of male and female undergraduates in Sri Lanka were significantly lower than that of figures obtained from an undergraduate sample in the USA (27). In the USA sample $(\mathrm{N}=539)$, the mean values on the measure of sexual compulsivity were $16.36(S D=$ $5.62)$ for males and $12.42(S D=2.82)$ for females $(p$ $<0.01)$. This indicates the low prevalence of sexual compulsive behaviors among undergraduates in Sri Lanka compared to the undergraduates in the USA. The culture and the university environment that the Sri Lankan undergraduates experience may not be conducive to have pre-marital sexual engagements. Unhealthy behaviors such as substance use and suicidal ideation seem to be associated with "excessive sex" in this population. Large scale welldesigned surveys are needed to confirm the results that we observed.

\section{Discussion}

Results of the research studies discussed in this paper suggest that a significant proportion of late adolescent school children in the country is exposed to unsafe sexual practices. The prevalence of unsafe sexual behavior would most probably be higher among out-of-school adolescents compared to such rates observed in this school-going population. Thus, a considerable proportion of young people in the country are at risk of developing sexually ill-health conditions. Males were more likely than females to engage in sexual activities and it could be attributable to higher likelihood of males being exposed to society in general, and to sexual stimuli in particular, compared to females. A male's greater experience with substance abuse may also play a role. Results also indicate that males are more vulnerable to being exposed to more risky sexual activities including commercial sex and forced sex. Close supervision by parents of their children's behavior seems to protect children from being 
exposed to unsafe sexual practices. In addition to these factors, early puberty, the rising age at marriage, urbanization, availability of contraception and the limited availability of sex education and counseling services are some of the major factors associated with sexual risk-taking behavior of young people in Sri Lanka $(11,17,18)$. Poor family environment, substance use, lack of parental monitoring, and psychopathology such as suicidal ideation are found to be associated with child sexual abuse in this target population. Further research is needed to better understand the causal relationships among these factors.

Given that a considerable proportion of late adolescent school children is sexually active and not motivated to seek sexual health advice from trustworthy and reliable sources, there is a need to identify what factors bar them from seeking such advice. Such research can guide prevention and intervention programs in this young population. Out-of-control sexual behavior in young people seems to be an emerging public health problem in the west. Westernization of the society, increasing use of alcohol and other substances, urbanization and advances in the communication field may motivate adolescents and young people in Sri Lanka to get addicted to unhealthy sexual behaviors that are prevalent in the western society. Our study conducted on out-of-control sexual behaviors using a sample of undergraduates in the country, probably be the first and only investigation that has explored the out-of-control sexual behaviors in young people. However, the information that we obtained from that survey is very limited, and there is a need to develop theoretically sound research to understand out-of -control-sexual behavior and associated psychological and environmental factors in young people.

\section{Conclusions and Recommendations}

A significant proportion of young people in Sri Lanka are at risk of developing ill-health conditions related to their sexual behavior. Thus, sexual health of young people should be one of the top priorities in the nations' health agenda. The following recommendations based on the research findings are made with the aim of controlling the occurrence of unhealthy sexual behaviors in young people in this country.
1. Recognize the relative importance of sex research in the contemporary Sri Lankan society. Replicate the current studies in ethically diverse youth populations. Young people, especially females, are observed to be particularly vulnerable to sexual coercion and violence as they age. A considerable amount of further research is needed that sensitively explore the levels, patterns, nature and extent of sexual coercion and violence.

2. School sex education program is a vital component of community responsibility. Sex education for young people must always be culturally appropriate and greater attention should be paid to psycho-social and environmental issues related to youth sexuality. Provide adequate training, not only in physical dimensions, but also in social, emotional, spiritual and environmental dimensions as well, in sexual health to all professionals who deal with sexual issues in young people, encourage them to use this training, and ensure that they are reflective of the populations they serve. Encourage the implementation of preventive strategies that have been adequately evaluated and shown to be effective. Ensure the availability of support services that promote both awareness and prevention of sexual abuse and coercion.

3. Uncontrolled sexual behavior and personal dispositions toward such behavior of young people need to be investigated. Partnership research with community organizations is needed in this respect; cognitive and behavioral impact of sexual activities needs to be investigated further, incorporating mediating variables such as sexual behavior; and finally, cross-cultural validation of these findings is needed.

\section{References}

1. Fathalla MF, Sinding SW, Rosenfield A, Fathalla MM, Sexual and reproductive health for all: a call for action, Lancet, 2006, 368: 2095-100.

2. WHO. The World Health Report 2005: Make every mother and child count, WHO, Geneva, 2005. 
3. U.S. Department of Health and Human Services. Healthy People 2010: Understanding and Improving Health. $2^{\text {nd }}$ Washington, DC: U.S. Government Printing Office, November 2000.

4. WHO. Fact Sheet No 110: Sexually transmitted diseasesRevised 2007. Available at http://www.who.int/ mediacentre/factsheets/fs110/en/

5. WHO. Unsafe abortion: global and regional estimates of incidence of unsafe abortion and associated mortality in 2003( $5^{\text {th }}$ ed). WHO, Geneva, 2007.

6. WHO. Comparative risk assessment: Child sexual abuse. WHO Collaborating Centre for Evidence and Health Policy in Mental Health: Sydney, Australia, 2001.

7. PAHP/WHO. Promotion of Sexual health: Recommendations for actions. Proceedings of a Regional Consultation Antigua Guatemala, Guatemala, 2000.

8. Ministry of Health Care and Nutrition. Annual Health Bulletin 2003, Colombo, Sri Lanka. State Printing Corporation.

9. UNAIDS/WHO. AIDS epidemic update. Geneva, Switzerland: Joint United Nations Programme on AIDs and WHO, 2003.

10. De Silva I, Rankapuge L, Perera R. Induced abortion in Sri Lanka: Who goes to providers for pregnancy termination; in Demography of Sri Lanka: Issues and Challenges, Department of Demography, University of Colombo, 2000.

11. De Zoysa P. Child sexual abuse in Sri Lanka: The current state of affairs and recommendations for the future. Journal of Child Sexual Abuse 2002; 11: 97-113.

12. De Silva DGH. Child abuse in Sri Lanka. In: SchwartzKenny BM, McCauley M, Epstein MA, eds. Child Abuse: a global view. Westport, USA: Greenwood Press, 2001.

13. UNAIDS. AIDS epidemic update 2005. Geneva, UNAIDS, WHO, 2005.

14. UNICEF/ UNAIDS/ WHO. Young people and HIV/AIDS -opportunity in crisis, New York, UNICEF, 2002.

15. WHO. The second decade: Improving adolescent health and development, Geneva, Switzerland: WHO, 2001.

16. Perera B, Fonseka PHG. Sexual behavior of advanced level students in southern Sri Lanka. Journal of the College of Community Physicians of Sri Lanka, 1998; 3: 13-17.
17. Silva KT, Schensul SL, Schensul JJ, Nastasi MW, De Silva A, Sivayoganathan C, et al. Youth and sexual risk in Sri Lanka. Women and AIDS research program Phase II, research report series No. 3. Washington, DC: International Center for Research on Women, 1997.

18. Perera B, Reece M. Sexual behavior of young adults in Sri Lanka: Implications for HIV prevention, AIDS Care 2006; 18: 497-500.

19. Goonawardane M. Teenage pregnancy. Sri Lanka Journal of Obstetrics and Gynecology, 2001;23: 11-14.

20. Miles GM. "Children don't do sex with adults for pleasure": Sri Lankan children's views on sex and sexual exploitation. Child Abuse and Neglect, 2000; 24: 995-1003.

21. Perera B, Ostbye T. Prevalence and correlates of sexual abuse reported by late adolescent school children in Sri Lanka. International Journal of Adolescent Medicine and Health, 2009; 21: 203-211.

22. Mellanby AR, Phelps AF, Crichton NJ, Tripp JH. School sex education: An experimental programme with educational and medical benefit. British Medical Journal 1995; 311: 414-417.

23. Carnes, P. Do not call it love: Recovery from sexual addiction. New York: Bantam Books, 1991.

24. Goodman, A. Sexual addiction. In: Lowinson JH; Ruiz P; Millman RB; Langrod JG (eds.) Substance abuse: A Comprehensive textbook, $4^{\text {th }}$ edition, Philadelphia: Williams \& Wilkins, 2005.

25. Kalichman, SC, Cain, D. The relationship between indicators of sexual compulsivity and high risk sexual practices among men and women receiving services from a sexually transmitted infection clinic. The Journal of Sex Research, 2004; 41: 235-241.

26. Kalichman SC, Rompa D. Sexual sensation seeking and sexual compulsivity scales: Reliability, validity, and predicting HIV risk behavior, Journal of Personality Assessment, 1995; 65: 586-601.

27. Perera B, Reece M, Monahan P, Billingham R, Finn P. (2009). Correlates of personal dispositions related to uncontrolled sex in College Students: An exploratory study. Sexual Addiction and Compulsivity 2009; 16: 131-145. 